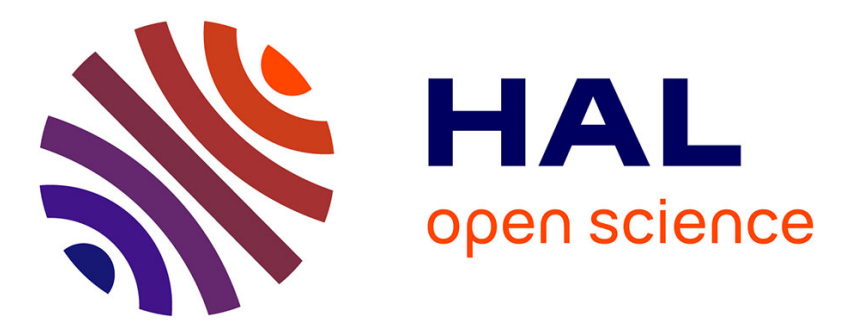

\title{
Long-term impaired memory following predatory stress in mice
}

Wissam El-Hage, G Griebel, Catherine Belzung

\section{To cite this version:}

Wissam El-Hage, G Griebel, Catherine Belzung. Long-term impaired memory following predatory stress in mice. Physiology \& behavior, 2006, 87 (1), pp.45 - 50. 10.1016/j.physbeh.2005.08.039 . hal-02525076

\section{HAL Id: hal-02525076 \\ https://hal-univ-tours.archives-ouvertes.fr/hal-02525076}

Submitted on 30 Mar 2020

HAL is a multi-disciplinary open access archive for the deposit and dissemination of scientific research documents, whether they are published or not. The documents may come from teaching and research institutions in France or abroad, or from public or private research centers.
L'archive ouverte pluridisciplinaire HAL, est destinée au dépôt et à la diffusion de documents scientifiques de niveau recherche, publiés ou non, émanant des établissements d'enseignement et de recherche français ou étrangers, des laboratoires publics ou privés. 
El-Hage W, Griebel G, Belzung C. Long-term impaired memory following predatory stress in mice. Physiology \& Behavior 2006;87(1):45-50._doi:10.1016/j.physbeh.2005.08.039

\title{
Long-term impaired memory following predatory stress in mice
}

\author{
WISSAM EL HAGE ${ }^{\mathbf{a b}}$, GUY GRIEBEL ${ }^{\mathbf{c}}$ AND CATHERINE BELZUNG ${ }^{\mathbf{a}}$
}

a EA3248 \& IFR135, Université François Rabelais, Faculté Sciences et Techniques, Parc Grandmont, 37200 Tours, France

b Clinique Psychiatrique Universitaire, CHRU Tours, 37044 Tours Cedex 1, France

c CNS Research Department, Sanofi-Synthelabo, 31 avenue Paul Vaillant-Couturier, 92220

Bagneux, France

\begin{abstract}
.
EL HAGE, W., G. GRIEBEL AND C. BELZUNG. Long-term impaired memory following predatory stress in mice. PHYSIOL BEHAV 2005. Brief exposure of mice to unavoidable predatory stimuli is associated with behavioral and neurochemical changes consistent with increased anxiety [Belzung C, El Hage W, Moindrot N, Griebel G, Behavioral and neurochemical changes following predatory stress in mice, Neuropharmacology, 41 (2001) 400-408] and produces short-term impaired learning restored by acute fluoxetine treatment, but not by diazepam [El Hage W, Peronny S, Griebel G, Belzung C, Impaired memory following predatory stress in mice is improved by fluoxetine, Prog Neuropsychopharmacol Biol Psychiatry, 28 (2004) 123-128]. The present study investigated long-lasting changes induced by a unique unavoidable cat exposure in BALB/c mice on learning abilities using learning tests (radial maze, spatial configuration of objects recognition test). Results from the group comparison showed that predatory exposure induced significant learning disabilities in the radial maze (16 to 22 days poststressor) and in the spatial configuration of objects recognition test (26 to 28 days poststressor). These findings indicate that memory impairments may persist for extended periods beyond a predatory stress. This animal model of unique exposure of mice to unavoidable predatory stimuli has proven to be a useful model for the study of reactions to traumatic stress. ${ }^{1}$
\end{abstract}

\section{Introduction}

Posttraumatic stress disorder (PTSD) is the only mental disorder that has the requirement of exposure to a traumatic stressor for diagnosis. PTSD symptomatology is characterized by late and lasting symptoms such as recollections, conditioned fear responses and psychological and physiological hyperarousal $(1,2)$. Clinically, PTSD patients commonly become physiologically aroused when they encounter trauma-related cues in their environment (3). Other symptoms include increased startle responsiveness, feeling on guard, intrusive (but not necessarily stimulus-evoked) memories and amnesia (4). Patients with PTSD have a variety of alterations in memory including deficits in explicit and implicit memory function. Evidence from a variety of studies $(5,6,7)$ shows a relationship between exposure to a traumatic stress and deficits in memory, attention, and visual spatial skills. In addition, stress

${ }^{1}$ Indexing terms: Animal model, BALB/c, learning impairments, radial maze, object recognition test, predatory stress, traumatic stress, anxiety, PTSD 
affects functions of new learning and memory that are mediated by the hippocampus $(8,9,10$, 11).

Animal models of psychiatric disorders have been useful in elucidating connections between behavioral symptoms and biological abnormalities and in suggesting possible treatment strategies. Above all, a valid animal model of PTSD must model a relevant original traumatic experience. If a stressor has relevance as a traumatic event, it should be uncontrollable (its onset and offset are unrelated to the organism's responses) and unpredictable (its occurrence is the same regardless of the events preceding it) (12). In fact, predictability, controllability and intensity determine the severity of subsequent PTSD (13). If a model has relevance for posttraumatic changes, it should meet at least some of the following criteria: even very brief stressors should be capable of inducing biological and behavioral sequels of PTSD; the PTSD-like sequels should persist or increase with the passage of time; the stressor should induce long-term bio-behavioral alterations that have the potential for bi-directional expression, and inter-individual variability in response to the stress should be present (14). Whenever possible, a unique animal model must be able to simulate the effects of trauma of an exogenous origin and to deal with immediate acute experience as well as long-lasting aftereffects of traumas. Those effects, as in the PTSD clinic, may last as long as 30 or 40 years $(15,16)$.

While PTSD has mental aspects that are beyond the scope of the animal researcher, animal models can be evaluated on two fronts: similarities in cause, and the degree of resemblance between abnormalities in the animal model and the objective symptoms of PTSD. It is widely acknowledged that the exposure of rodents to natural predators or to their odors may induce anxiety-like states $(17,18,19,20,21)$. Previous studies $(22,23)$ showed that predatory stress in mice produces short-term behavioral, neurochemical and cognitive changes consistent with symptoms associated with posttraumatic reactions. A recent study (24) showed long-lasting anxiogenic effects of predator exposure (cat) in mice. Moreover, this study suggest a graded response to severity of stress, as represented in human PTSD. Other animal models of traumatic stress using an external stressor are currently available such as an underwater trauma in rats (24), a brief electric shock with repeated exposures to situational reminders in mice $(26,27)$ or a single exposure to a cat in rats (17). The present study was designed to determine whether exposure to species-relevant life-threatening inescapable stress leads to long-lasting changes in memory functioning. Therefore, the cat, a natural rodent predator, is an appropriate life-threatening stressor that rodents recognize and to which they respond appropriately (28). The chosen strain (BALB/c) was found to display clear abnormal reactivity when exposed to predatory stimuli (22). This study investigated the relationship between a predatory stress and alteration in learning abilities in mice exposed to a cat using an 8 -arm radial maze and spatial configuration of objects recognition test (hippocampusdependent spatial memory tasks, except for the habituation period on the objects recognition test).

\section{Animals, Materials and Methods}

\subsection{Ethics}

All procedures described here fully comply with French legislation on research involving animal subjects. This research protocol adhered to recommendations by the European Community Council for the Ethical Treatment of Animals ( $\left.n^{\circ} 86 / 609 / E E C\right)$. 


\subsection{Animals}

Subjects were naïve male mice BALB/cByJIco aged 8 weeks at the time of cat exposure, and 9 to 16 weeks at the time of testing. They were obtained from Iffa-Credo (L'Arbresle, France). Animals were housed in groups of five in standard-sized cages $(30 \times 20 \times 14 \mathrm{~cm})$ containing a constant supply of food pellets and water. All animals were maintained under standard laboratory conditions $\left(21-23^{\circ} \mathrm{C}\right)$ and kept on a 12-hr light/dark cycle (light onset at 8 a.m.).

\subsection{Predatory exposure}

Mice were randomly assigned to exposed or control groups. Subjects of the exposed group were confronted individually with a cat during a 5-min session. The cat cage consisted of a polyvinyl chloride (PVC) box $(82 \times 56 \times 62 \mathrm{~cm})$ subdivided into two compartments, one containing the cat $(56 \times 56 \times 62 \mathrm{~cm})$, the other the mouse. Separation consisted of a transparent Plexiglas wall with holes allowing the cat to reach the other side with its paws. The cat (male, age 3 years; Iffa Credo, L'Arbresle, France) was placed in the exposure apparatus first. Then the mouse was introduced into the exposure apparatus. Timing of the test began at this point. The mice were not able to escape from this compartment or from the cat, though there was ample place to run from the cat. The cat approached and in some cases engaged in mild noninjurious predatory attacks on the mice. The mice were not physically injured. After five minutes of exposure to the cat, the mouse was put back in its cage first. On the cat exposure day, the control mice were handled once. Predatory stress or handling took place between $10 \mathrm{hr} 00$ and $15 \mathrm{hr} 00$.

\subsection{Testing schedule}

The choice of the testing schedule was determined by ethical considerations limiting the number of subjects. In experiment 1, we ran tests during 1 month poststressor. We measured spatial learning in the radial maze between 16 and 22 days poststressor $(n=29)$ and object recognition abilities 26, 27, and 28 days poststressor $(n=29)$. In experiment 2, we ran tests during 2 months poststressor in order to observe long-term changes. We measured spatial learning in the radial maze between 40 and 47 days poststressor $(n=30)$.

\subsection{Radial maze}

The radial maze $(29,30)$ was elevated $110 \mathrm{~cm}$ above the floor and consisted of a central circular platform measuring $30 \mathrm{~cm}$ in diameter. Eight open arms (48 cm long, $5 \mathrm{~cm}$ wide) radiated outwards at equal distances, $1 \mathrm{~cm}$ high sides surrounding each arm. Each arm formed a corridor leading to an $8-\mathrm{cm}$ square platform. A cup, 1-cm diameter, embedded in each platform, could contain a hidden 10-mg noodle reward. The maze was always oriented in space in the same way. It was placed on the floor of a spatially rich structured room. Twentyfour hours prior to training, the mice were deprived of food, but not of water; the weight loss reached 15 to $20 \%$ of the initial body weight by the start of testing. During training, body weight was kept at $80-90 \%$ of the pre-test value. The mice were first given two pretraining sessions at 24-hr intervals. They were placed in groups of five on the maze for $10 \mathrm{~min}$ per session with free access to the eight arms, which were provided with abundant food. Following pretraining, the animals were trained singly on 5 consecutive days, one session per day. Sessions were terminated when the animal had visited all 8 arms and eaten the rewards, or after 16 arms were visited (no matter what arms), or after a maximum of 15-min. When 
each mouse had completed testing, the maze was cleaned to remove fecal deposits and urine. An error was noted if an animal entered an arm previously visited during the same session. The number of errors and the rank of the first error (when the mouse re-enter in one visited arm) on each training day provided the measures of acquisition (e.g., a higher rank means a better learning ability).

\subsection{Spatial configuration of objects recognition test (SCORT)}

This paradigm utilizes the natural tendency of rodents to explore novel objects. Mice spend more time exploring the novel spatial configuration, suggesting that the familiar spatial configuration was recognized. The experiments suggest that rodents are able to recognize previously explored spatial configuration, remember the location in which objects are previously encountered, and are able to discriminate the relative recency in which objects were presented.

Each mouse was placed in the centre of a grey circular open field (diameter: $40 \mathrm{~cm}$, wall height: $30 \mathrm{~cm})$ made of PVC, with a black and white-striped cardboard pattern $(30 \times 20 \mathrm{~cm})$ nailed on one of the walls $(31,32)$. The floor was divided into one central and six peripheral parts of equal surface. The test room was dimly illuminated with a red light bulb. Three identical round metal objects (diameter: $2 \mathrm{~cm}$, height: $3 \mathrm{~cm}$ ) were displayed in a V-shaped configuration in the central part of the open field. The SCORT took place during four sessions separated by an interval of 15 -min, each session lasting $5 \mathrm{~min}$. During the first three sessions, the location of the objects remained the same. On the fourth session, the position of all three objects was changed to a straight-line configuration. We measured horizontal activity in the centre and perimeter (mean centre and peripheral entries). Afterwards, we calculated the centre ratio. The centre ratio is the number of entries into the centre divided by the total number of entries (centre + periphery).

\subsection{Statistical analysis}

The data was analyzed using non-parametric statistics. Comparisons between all exposure groups and controls were carried out using Mann-Whitney U-tests. Radial maze data were analyzed using Friedman tests for repeated measures. SCORT data were analyzed using Friedman test (sessions 1-3) and Wilcoxon test that aimed at comparing sessions 3 and 4 . All results were expressed as means ( \pm S.E.M.). Significance was assumed at the value $\mathrm{p}<0.05$.

\section{Results}

\subsection{Radial maze}

In experiment 1 (16-22 days poststressor), the mice of the control group learned the spatial configuration, since we observed a later occurrence of the first error (Friedman's $\chi^{2}=10.33$; d.f. $=4 ; p=0.035$ ), but not the mice of the stressed group (Friedman's $\chi^{2}=5.50 ;$ d.f. $=4$; $\mathrm{p}=0.239)$. The number of errors was higher in the stressed group $(7.43 \pm 0.68)$, with a significant difference $(\mathrm{U}=58, \mathrm{p}<0.05)$ from the control group $(5.20 \pm 0.79)$ at the fourth trial (Fig. 1a). This was corroborated by a lower first rank error in the stressed group (4.07 \pm 0.37$)$, which was significantly different $(\mathrm{U}=39.5, \mathrm{p}<0.05)$ from the control group $(6.0 \pm 0.42)$ at the fifth trial, indicating an earlier occurrence of the first error in the stressed group (Fig. 1b). In experiment 2 (40-47 days poststressor), we found no significant difference between the stressed and control groups in radial maze learning (results not presented). 


\subsection{Spatial configuration of objects recognition test (SCORT)}

In the SCORT (experiment 1), the stressed group was significantly different from control group for the number of entries to the centre $(U=67, p<0.05)$ at the first trial, for object rearings $(U=45.5, p<0.05)$ at the third trial, and for centre ratio at the first $(U=63, p<0.05)$ and the second trial $(\mathrm{U}=67, \mathrm{p}<0.05)$. As seen in Fig. 2a, in the control group, exploration of the centre decreased with habituation (Friedman's $\chi^{2}=9.57$; d.f. $=2 ; p=0.008$ ), and increased with object displacement $(\mathrm{Z}=1.71 ; \mathrm{p}=0.043)$, indicating a good spatial learning. The number of entries to the centre by the exposed mice increased progressively (Friedman's $\chi^{2}=0.93$; d.f. $=2$; $\mathrm{p}=0.627)$ without any effect of object displacement $(\mathrm{Z}=0.87 ; \mathrm{p}=0.191)$, indicating an absence of spatial learning in this task. As seen in Fig. $2 b$, the control mice familiarized themselves with the objects during the first three sessions of habituation (Friedman's $\chi^{2}=7.11$; d.f. $=2$; $\mathrm{p}=0.028)$ but not during the final one $(\mathrm{Z}=2.66 ; \mathrm{p}=0.004)$, while the exposed mice increased object rearing during habituation (Friedman's $\chi^{2}=0.70$; d.f. $=2 ; p=0.705$ ) but not when the objects were displaced on the fourth trial $(\mathrm{Z}=1.02 ; \mathrm{p}=0.153)$. In Fig. $2 \mathrm{c}$, the centre ratio of the exposed mice increased with no effect of object displacement $(\mathrm{p}=\mathrm{ns})$. We noted also a significant difference in horizontal activity (in the centre and perimeter) between the exposed mice and the control group at the first trial $(\mathrm{U}=63 ; \mathrm{p}=0.033)$ (data not shown).

\section{Discussion}

In the present study, a unique exposure of mice to unavoidable ethologically relevant predatory stress is found to be associated with long-term significant impairments in learning (during only one month). A single exposure of mice to a cat induced spatial learning impairment on the radial maze (16 to 22 days poststressor) and on the SCORT (26 to 28 days poststressor). On the radial maze, control mice were able to decrease the number of errors during learning sessions and to improve the rank of the first error. The stressed mice failed to improve their spatial navigation on the radial maze. On the SCORT, control mice learned the spatial configuration during the habituation period and were able to discriminate between new and familiar spatial configuration. The stressed mice failed to learn the spatial configuration on the SCORT, which might reflect an habituating reticence to enter to the centre of the apparatus based on an increased anxiety.

In the present study, the learning component did not consist of any stressful stimulus, did not implicate somatomotor activity, but it measures long-term memory. The predatory exposure did not cause any noticeable physical harm that could explain the observed differences. The choice of the stressor (e.g., species-relevance) and of the response (e.g., emotional reactivity) constitutes important factors providing a differential model of psychiatric disorders. We used the $\mathrm{BALB} / \mathrm{c}$ strain, as it is sensitive and notably reactive to predatory exposure, and may therefore appear to be a more suitable model of pathological anxiety $(31,33,34,35)$. In a previous study (22) BALB/c was found to be a reactive strain to predatory exposure.

Stress appears to reduce the efficiency of hippocampal-related processing. In fact, the radial maze and the SCORT are hippocampus-dependent (except during the habituation period). However, the present results show a very clear habituation for controls, and none for the exposed mice, suggesting that the deficits of the exposed mice are not just in hippocampaldependent learning/memory functions. Performance of the stressed group was impaired relative to that of the control group. In the radial maze and in the SCORT, the stressed mice failed to learn or to explore spatial configuration during the test session. These results are similar to those of Park et al. (36) who found impaired habituation to a novel environment in 
the open field in rats exposed to a cat, heightened anxiety, and impaired learning and memory in their rate of spatial learning. Stress has effects on functions of new learning and memory that are mediated by the medial prefrontal cortex (37) or the hippocampal-related processing, but does not produce the equivalent of a complete hippocampal lesion $(36,38)$. Our findings of impaired memory after predatory stress in mice parallel human work in that people with PTSD exhibit impaired cognitive functioning $(9,10,39)$, but their deficits are not nearly as severe as those found in people with extensive damage to the hippocampus (40).

These poststressor cognitive modifications may relate to anxiety and may be explained by a lasting abnormal emotional reactivity in exposed mice, which must be confirmed in a further specific experiment. The results of this study are encouraging as a recent study (24) with Swiss Webster mice showed that feline predator stress stimuli produce a graded and lasting increase in anxiety like (risk assessment) behavior in elevated plus maze. Anxiety in PTSD has been found to persist independently of events that are reminiscent of the trauma. The persistence of anxiety symptoms beyond 7 days in rodents may model chronic PTSD-related anxiety $(17,41)$. Previous work $(22)$ has showed this confrontation with a cat induced posttraumatic changes that lasted at least one hour after the stressful event and mimicked some features of acute stress disorder including anxiogenic-like responses, avoidance of feces (abolished after repeated administration of serotonin reuptake inhibitor fluoxetine), and increased rates of monoamines (noradrenaline and serotonin) in the hippocampus. The present study using an ethologically relevant stress fully agree with previous studies in rodents showing lasting effects of cat exposure $(42,43)$. We found a number of symptoms of learning impairments arising together or in close temporal proximity after predatory exposure in mice. This suggests that confrontation with the cat induced changes that lasted one month after the stressful event. However, further studies investigating behavioral and neurochemical modifications in others strains of mice following predator exposure will be necessary to confirm our findings.

\section{Conclusion}

This work showed long-term impaired memory following predatory stress in BALB/c mice. A 5-min unique ethologically relevant predatory exposure in mice resulted in long-lasting impaired memory indicating the relevance of this exposure as a traumatic stress and for its use as a model of aspects of PTSD. Further studies should confirm our results and supply pharmacological and/or neuroendocrine arguments.

\section{Acknowledgments}

We would like to thank Raymond Jegat who built the apparatus and for his technical help.

\section{References}

1. American Psychiatric Association, 1980. Diagnostic and Statistical Manual of Mental Disorders, Third ed. American Psychiatric Press, Washington, DC.

2. American Psychiatric Association, 1994. Diagnostic and Statistical Manual of Mental Disorders, Fourth ed. American Psychiatric Press, Washington, DC.

3. Wolfe, J., Schlesinger, L. K. Performance of PTSD patients on standard tests of memory. Implications for trauma. Ann. N. Y. Acad. Sci. 1997, 821:208-218. 
4. Bremner, J. D., Vermetten, E., Southwick, S. M., Krystal, J. H., Charney, D. S. Trauma, memory, and dissociation: an integrative formulation. In: Bremner, J. D., Marmar, C. A., eds. Trauma, memory, and dissociation. Washington, DC: American Psychiatric Press; 1998:p365-402.

5. Gilbertson, M. W., Gurvits, T. V., Lasko, N. B., Orr, S. P., Pitman, R. K. Multivariate assessment of explicit memory function in combat veterans with posttraumatic stress disorder. J. Trauma. Stress 2001, 14(2):413-432.

6. McNally, R. J. Experimental approaches to cognitive abnormality in posttraumatic stress disorder. Clin. Psychol. Rev. 1998, 18(8):971-982.

7. Vasterling, J. J., Duke, L. M., Brailey, K., Constans, J. I., Allain, A. N., Jr, Sutker, P. B. Attention, learning, and memory performances and intellectual resources in Vietnam veterans: PTSD and no disorder comparisons. Neuropsychology 2002, 16(1):5-14.

8. Beuzen, A., Belzung, C. Link between emotional memory and anxiety states: A study by principal component analysis. Physiol. Behav. 1995, 58:111-118.

9. Bremner, J. D., Scott, T. M., Delaney, R. C., Southwick, S. M., Mason, J. W., Johnson, D. R., Innis, R. B., McCarty, G., Charney, D. S. Deficits in short-term memory in posttraumatic stress disorder. Am. J. Psychiatry 1993, 150:1015-1019.

10. Bremner, J. D., Randall, P., Scott, T. M., Bronen, R. A., Seibyl, J. P., Southwick, S. M., Delaney, R. C., McCarty, G., Charney, D. S. Magnetic resonance imaging-based measurement of hippocampal volume in patients with combat-related posttraumatic stress disorder. Am. J. Psychiatry 1995, 152:973-981.

11. Lupien, S. J., Lepage, M. Stress, memory, and the hippocampus: can't live with it, can't live without it. Behav. Brain Res. 2001, 127(1-2):137-158.

12. Foa, E. B., Zinbarg, R., Rothbaum, B. O. Uncontrollability and unpredictability in post-traumatic stress disorder: an animal model. Psychol. Bull. 1992, 112(2):218-238.

13. Ballenger, J. C., Davidson, J. R. T., Lecrubier, Y., Nutt, D. J., Foa, E. B., Kessler, R. C., McFarlane, A. C., Shalev, A. Y. Consensus statement on posttraumatic stress disorder from the international consensus group on depression and anxiety. J. Clin. Psychiatry 2000, 61(Suppl. 5):60-66.

14. Yehuda, R., Antelman, S. M. Criteria for rationally evaluating animal models of posttraumatic stress disorder. Biol. Psychiatry 1993, 33:479-486.

15. Speed, N., Engdahl, B., Schwartz, J., Eberly, R. Posttraumatic stress disorder as a consequence of the POW experience. J. Nerv. Ment. Dis. 1989, 177:1447-1453.

16. Sutker, P. B., Winstead, D. K., Galina, Z. H., Allain, A. N. Cognitive deficits and psychopathology among former prisoners of war and combat veterans of the Korean conflict. Am. J. Psychiatry 1991, 148:67-72.

17. Adamec, R. E., Shallow, T. Lasting effects on rodent anxiety of a single exposure to a cat. Physiol. Behav. 1993, 54:101-109.

18. Berton, F., Vogel, E., Belzung, C. Modulation of mice anxiety in response to cat odor as a consequence of predators diet. Physiol. Behav. 1998, 65:247-254.

19. Blanchard, R. J., Blanchard, D. C., Weiss, S. M., Meyer, S. The effects of ethanol and diazepam on reactions to predatory odors. Pharmacol. Biochem. Behav. 1990, 
$35: 775-780$.

20. Hogg, S., File, S. E. Regional differences in rat benzodiazepine binding in response to novelty and cat odour. Neuropharmacology 1994, 33:865-868.

21. Kavaliers, M., Wiebe, J. P., Galea, L. A. M. Reduction of predator odor-induced

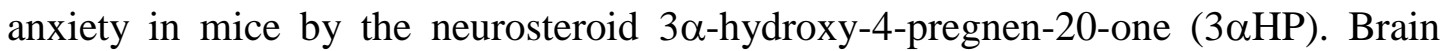
Res. 1994, 645:325-329.

22. Belzung, C., El Hage, W., Moindrot, N., Griebel, G. Behavioral and neurochemical changes following predatory stress in mice. Neuropharmacology 2001, 41:400-408.

23. El Hage, W., Peronny, S., Griebel, G., Belzung, C. Impaired memory following predatory stress in mice is improved by fluoxetine. Prog. Neuropsychopharmacol. Biol. Psychiatry 2004, 28(1):123-128.

24. Adamec R., Walling S., Burton P. Long-lasting, selective, anxiogenic effects of feline predator stress in mice. Physiol. Behav. 2004, 83(3):401-410.

25. Richter-Levin, G. Acute and long-term behavioral correlates of underwater trauma potential relevance to stress and post-stress syndromes. Psychiatry Res. 1998, 79:7383.

26. Maier, S. F. Exposure to the stressor environment prevents the temporal dissipation of behavioral depression/learned helplessness. Biol. Psychiatry 2001, 49:763-773.

27. Pynoos, R. S., Ritzman, R. F., Steinberg, A. M., Goenjian, A., Prisecaru, I. A behavioral animal model of PTSD featuring repeated exposure to situational reminders. Biol. Psychiatry 1996, 39:129-134.

28. Blanchard, R. J., Nikulina, J. N., Sakai, R. R., McKittrick, C., McEwen, B., Blanchard, D. C. Behavioral and endocrine change following chronic predatory stress. Physiol. Behav. 1998, 63(4):561-569.

29. Beuzen, A., Belzung, C., Roullet, P. Drug effects in a radial maze designed for dissociation of cues used by mice. Pharmacol. Biochem. Behav. 1994, 48:23-29.

30. Roullet, P., Lassalle, J. M., Jegat R. A study of behavioral and sensorial bases of radial maze learning in mice. Behav. Neural Biol. 1993, 59(3):173-179.

31. Belzung, C., Griebel, G. Measuring normal and pathological anxiety-like behaviour in mice: a review. Behav. Brain Res. 2001, 125:141-149.

32. Poucet, B. Object exploration, habituation, and response to a spatial change in rats following septal or medial frontal cortical damage. Behav. Neurosci. 1989, 103(5):1009-1016.

33. Belzung, $\mathrm{C}$. The genetic basis of the pharmacological effects of anxiolytics: a review based on rodent models. Behav. Pharmacol. 2001, 12:451-460.

34. Griebel, G., Belzung, C., Misslin, R., Vogel, E. The free-exploratory paradigm: An effective method for measuring neophobic behaviour in mice and testing potential neophobia reducing drugs. Behav. Pharmacol. 1993, 4:637-644.

35. Griebel, G., Belzung, C., Perrault, G., Sanger, D. J. Differences in anxiety-related behaviours and in sensitivity to diazepam in inbred and outbred strains of mice. Psychopharmacology (Berl.) 2000, 148:164-170.

36. Park, C. R., Campbell, A. M., Diamond, D. M. Chronic psychosocial stress impairs learning and memory and increases sensitivity to yohimbine in adult rats. Biol. 
Psychiatry 2001, 50(12):994-1004.

37. Bremner, J. D. Neuroimaging studies in post traumatic stress disorder. Curr. Psychiatry Rep. 2002, 4:254-263.

38. Diamond, D. M., Park, C. R. Predator exposure produces retrograde amnesia and blocks synaptic plasticity. Progress toward understanding how the hippocampus is affected by stress. Ann. N. Y. Acad. Sci. 2000, 911:453-455.

39. Yehuda, R., Keefe, R. S., Harvey, P. D., Levengood, R. A., Gerber, D. K., Geni, J., Siever, L. J. Learning and memory in combat veterans with posttraumatic stress disorder. Am. J. Psychiatry 1995, 152:137-139.

40. Zola-Morgan, S., Squire, L. R., Rempel, N. L., Clower, R. P., Amaral, D. G. Enduring memory impairment in monkeys after ischemic damage to the hippocampus. J. Neurosci. 1992, 12:2582-2596.

41. Adamec, R., Kent, P., Anisman, H., Shallow, T., Merali, Z. Neural plasticity, neuropeptides and anxiety in animals - implications for understanding and treating affective disorder following traumatic stress in humans. Neurosci. Biobehav. Rev. 1998, 23:301-318.

42. Blanchard, R. J., Blanchard, D. C. Antipredator defensive behaviours in a visible burrow system. J. Comp. Psychol. 1989, 103:70-82.

43 Kavaliers, M., Colwell, D. D. Sex differences in opioid and non-opioid mediated predator- induced analgesia in mice. Brain Res. 1991, 568:173-177. 
Figure 1. a) Effects of predatory stress on the mean number $( \pm$ S.E.M. $)$ of errors in the exposed group versus control during acquisition of the food-reinforced radial maze task, 16-22 days poststressor $(n=29)$. $* \mathrm{p}<0.05$ versus control group; b) Effects of predatory stress on the mean number $( \pm$ S.E.M.) of rank error in the exposed group versus control during acquisition of the food-reinforced radial maze task, 16-22 days poststressor $(n=29)$. $* \mathrm{p}<0.05$ versus control group.

a)

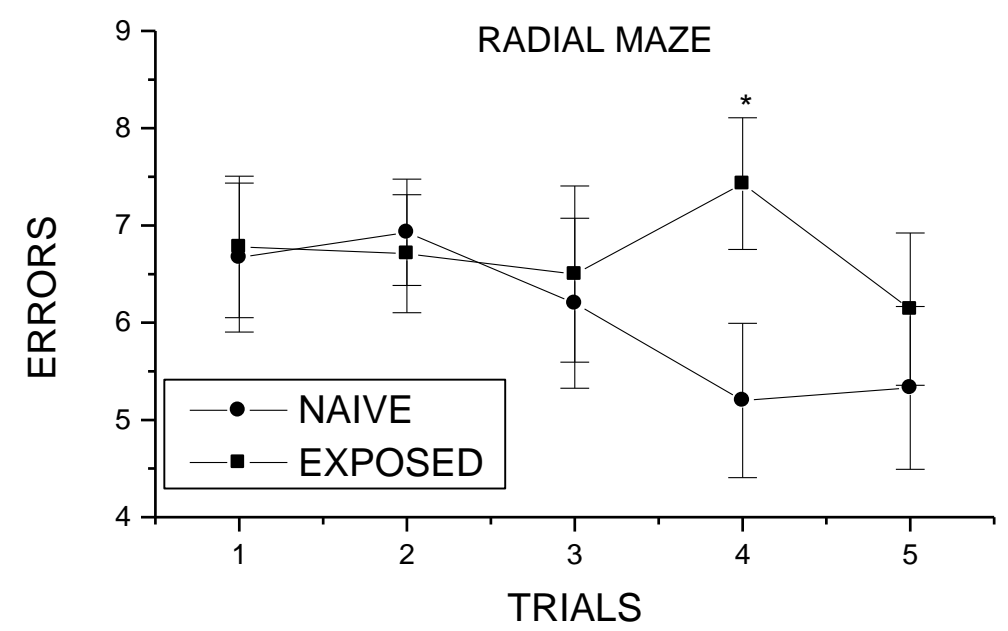

b)

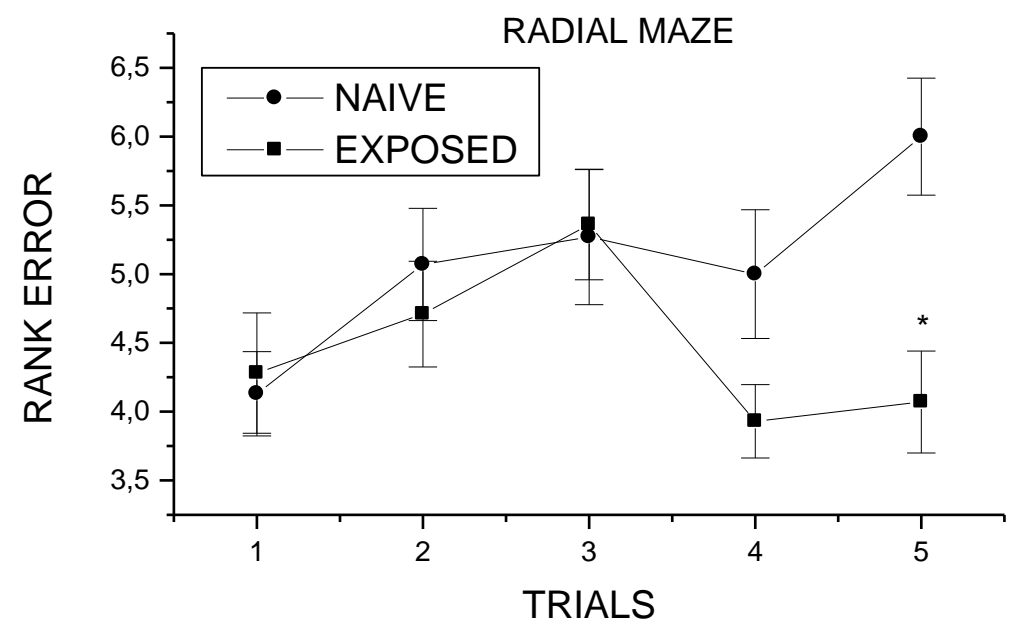


Figure 2. a) Effects of predatory stress on the mean number ( \pm S.E.M.) of entries to the centre during habituation (sessions 1-3) or after object displacement (session 4) in Balb/c mice in the SCORT 26-28 days poststressor $(n=29)$; b) Effects of predatory stress on the mean number $( \pm$ S.E.M. $)$ of objects rearing during habituation (sessions 1-3) or after object displacement (session 4) in Balb/c mice in the SCORT 26-28 days poststressor $(n=29)$; c) Effects of predatory stress on the mean number ( \pm S.E.M.) of ratio centre during habituation (sessions 1-3) or after object displacement (session 4) in Balb/c mice in the SCORT 26-28 days poststressor $(n=29)$. Centre ratio is the number of entries into the centre divided by this number added to perimeter activity. $* \mathrm{p}<0.05$ versus control group.

a)

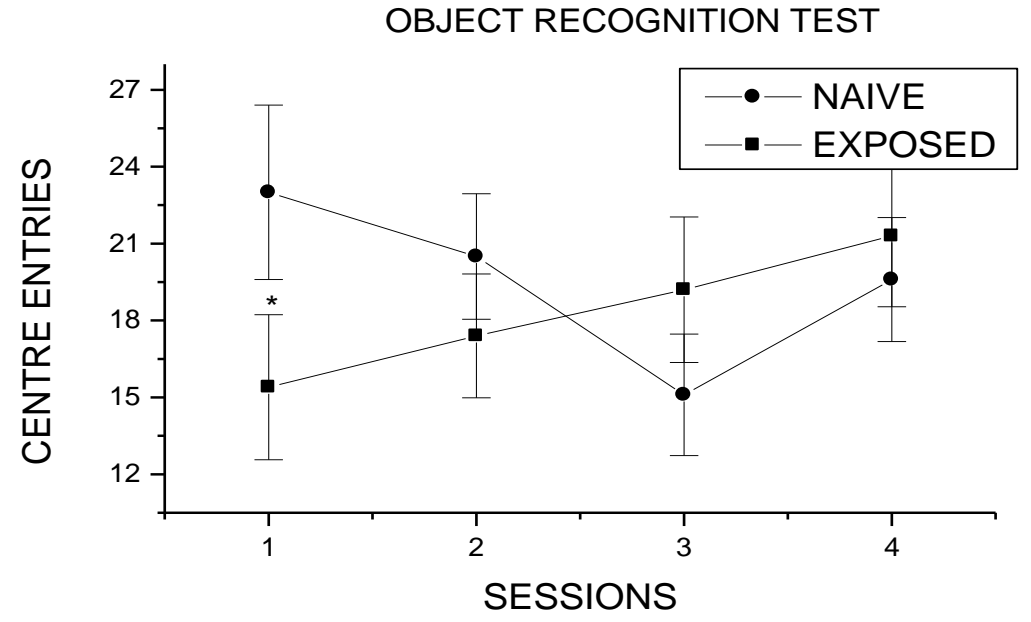

b)

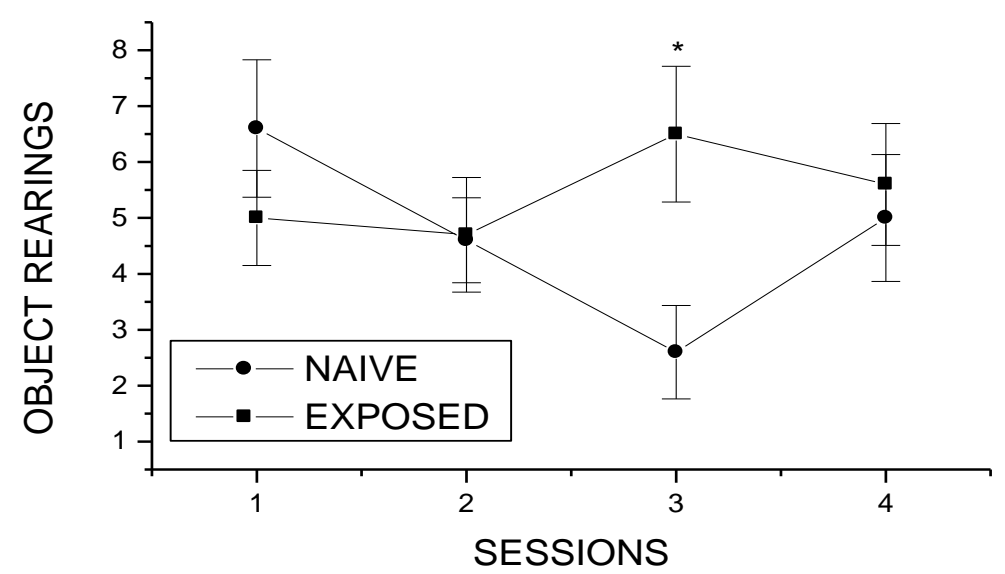

c)

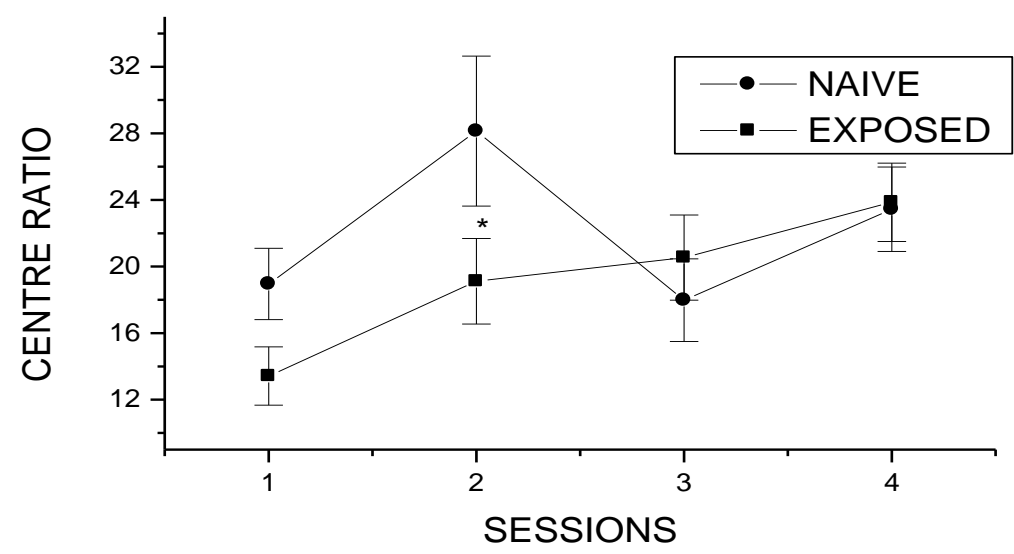

